\title{
On the Use of Classic Epidemiological Formulae for Estimating the Intensity of Endemic Malaria Transmission by Vectors in the Amazon
}

\author{
FSM Barros ${ }^{1}$, WP Tadel ${ }^{2}$, ME Arruda ${ }^{3}$, NA Honório ${ }^{4}$ \\ ${ }^{1}$ Depto de Zoologia, Univ Federal de Pernambuco, Recife, PE, Brasil \\ ${ }^{2}$ Instituto Nacional de Pesquisas da Amazônia, Manaus, AM, Brasil \\ ${ }^{3}$ Depto de Imunonologia, Centro de Pesquisas Aggeu Magalhães, Fundação Oswaldo Cruz, Recife, PE, Brasil \\ ${ }^{4}$ Lab de Transmissores de Hematozoários, Instituto Oswaldo Cruz, Fundação Oswaldo Cruz, Rio de Janeiro, RJ, Brasil
}

\section{Keywords}

Brazil, epidemiology, sporozoite rate

\section{Correspondence}

Nildimar A Honório, Lab de Transmissores de Hematozoários, Instituto Oswaldo Cruz, Fundação Oswaldo Cruz, Rio de JaneiroAv. Brasil, 4036, 2104036, Rio de Janeiro, RJ, Brasil; honorio@ioc.fiocruz.br

Edited by Neusa Hamada - INPA

Received 7 November 2011 and accepted 14 June 2012

Published online 4 September 2012

(C) Sociedade Entomológica do Brasil 2012

\begin{abstract}
Although various reports have described entomological inoculation rates of malaria vector species, most were limited to providing descriptive field data. Here, we report biting rates and survival data for two important malaria vectors in the Amazon, Anopheles darlingi (Root) and Anopheles albitarsis E (Lynch-Arribalzaga) (Diptera: Culicidae), in the state of Roraima, Brazil. We calculated theoretical sporozoite infection rates and critical vector biting rates for these species during 1 year, comprising six bimestrial collections. Anopheles darlingi had higher sporozoite rates and lower critical biting rates, indicating that it would be the more efficient vector at the beginning of epidemic malaria transmission. Our data, together with compiled information from the literature in the Amazon, suggest that epidemic malaria transmission may be initiated by the primary vector, such as $A$. darlingi, while secondary vectors, such as $A$. albitarsis $\mathrm{E}$, may only become epidemiologically important when there is an increase in the prevalence of human malaria. We propose that mathematical modeling may be able to quantify the relative importance of secondary vector species in malaria epidemiology.
\end{abstract}

\section{Introduction}

Malaria is the most important vector-borne disease in the Amazon Basin. In the Brazilian Amazon, Anopheles darlingi (Root) has been for long implicated as the most important vector (Póvoa et al 2000a, Tadei \& Thatcher 2000, Galardo et al 2007), while other species have been pointed as important local vectors (Arruda et al 1986). Several studies have determined sporozoite infection rates, i.e. the proportion of infected mosquitoes (Beier et al 1990) in this region (Vasconcelos et al 2002, Flores-Mendoza et al 2004, Póvoa et al 2006, Magris et al 2007, Gil et al 2007, Girod et al 2008, Moreno et al 2009). These studies have also identified other species as potential local vectors, such as Anopheles albitarsis E (Lynch-Arribálzaga) (Póvoa et al
2006), Anopheles marajoara (Galvão \& Damasceno) and Anopheles neomaculipalpus (Curry) (Moreno et al 2009). These same studies have also estimated entomological inoculation rates (EIR) of malaria-infected species. The number of infectious bites received per day by a human EIR is the product of the sporozoite rate and the man-biting rate (WHO 1975) and describes the intensity of transmission (Burkot \& Graves 1995). The sporozoite rates are usually directly obtained by examining the human landing catches with immunological assays, such as enzyme-linked immunosorbent assay (ELISA), Vec-Test ${ }^{\mathrm{TM}}$ antigen panel assay (Medical Analysis Systems, Inc., Fremont, CA, USA) or other techniques. The man-biting rate can be measured by direct captures on human bait. Reports have traditionally been limited to summarizing data on the malaria vector 
species. These studies usually have described higher EIR in A. darlingi. The efficiency of other species as malaria vectors in the Amazon has been questioned. In the state of Amazonas, for example, human transmission was only found in areas infested with $A$. darlingi (Tadei \& Thatcher 2000).

In Boa Vista, Roraima, in the northern Brazilian Amazon, both $A$. darlingi and $A$. albitarsis $E$ are considered important vectors of malaria (Vasconcelos et al 2002, Póvoa et al 2006). In here, classic epidemiological models using biting rates and survival data of anopheline species obtained from field data enabled the determination of theoretical sporozoite infection rates that would be expected in low transmission zones. Critical vector biting rates represent the man biting rates above which a species will increase the number of human malaria cases, considering a low prevalence of malaria in the area (Macdonald 1957). In this paper, an attempt is made to use these theoretical infection rates to compare the role that each vector species would have in malaria dissemination within low transmission zones.

\section{Material and Methods}

\section{Study area}

The study site has been previously characterized (Barros \& Honório 2007). Briefly, the study site is located in Roraima, northernmost state of Brazil (Fig 1). Ecoclimatic and geomorphological maps have been elaborated for this state and the influence of such variables on the distribution of anophelines has been studied (Barros et al 2007a, RosaFreitas et al 2007). The study area, named Jardim das Copaíbas, is located $5 \mathrm{~km}$ south of the center of Boa Vista $\left(02^{\circ} 45^{\prime} 28^{\prime \prime} \mathrm{N}, 60^{\circ} 42^{\prime} 18^{\prime \prime} \mathrm{W}\right)$, the capital of Roraima. The entire municipality of Boa Vista, the most populated of Roraima, had an annual parasitological index (API, malaria cases per 1,000 persons per year) of 23.4 in 2010 and 3.9 in 2004, at the time of study. The API in 2004 was approximately 230 in the study area, where malaria is hypoendemic. Spleen rates were $<5 \%$, in children aged $2-9$ years (unpublished information). House spraying was not routinely performed and the last dose had been applied more than 6 months before the collections for the present study started.

Malaria cases increase during the middle of the wet season (July) and can remain high until November (Vasconcelos et al 2002, Póvoa et al 2006). Although savanna is the predominant vegetation in northeastern Roraima, dense riparian gallery forests occur. Riversides become partly flooded during the rainy season. Temperatures are permanently high throughout Roraima, with little variation during the year, i.e., around $27.8^{\circ} \mathrm{C}$ (60-year average: 1939-1999) (Barbosa et al 1997). Relative humidity is also steady year-round. Relative humidity is around $73.8 \%( \pm 3.6)$ in the savanna.

\section{Meteorological variables}

Data on rainfall was obtained from a station located $9.6 \mathrm{~km}$ away from the study site. Rainfall was $1,181 \mathrm{~mm}$ from August 2003 to July 2004, but markedly concentrated from May to July, with heavier rains occurring. Temperature and relative humidity were also monitored in the field on every night of collection. Mean daily temperature varied from $26^{\circ} \mathrm{C}$ in July to $29^{\circ} \mathrm{C}$ in January (Table 1). Mean relative humidity was $54.8 \%( \pm 5.4)$.

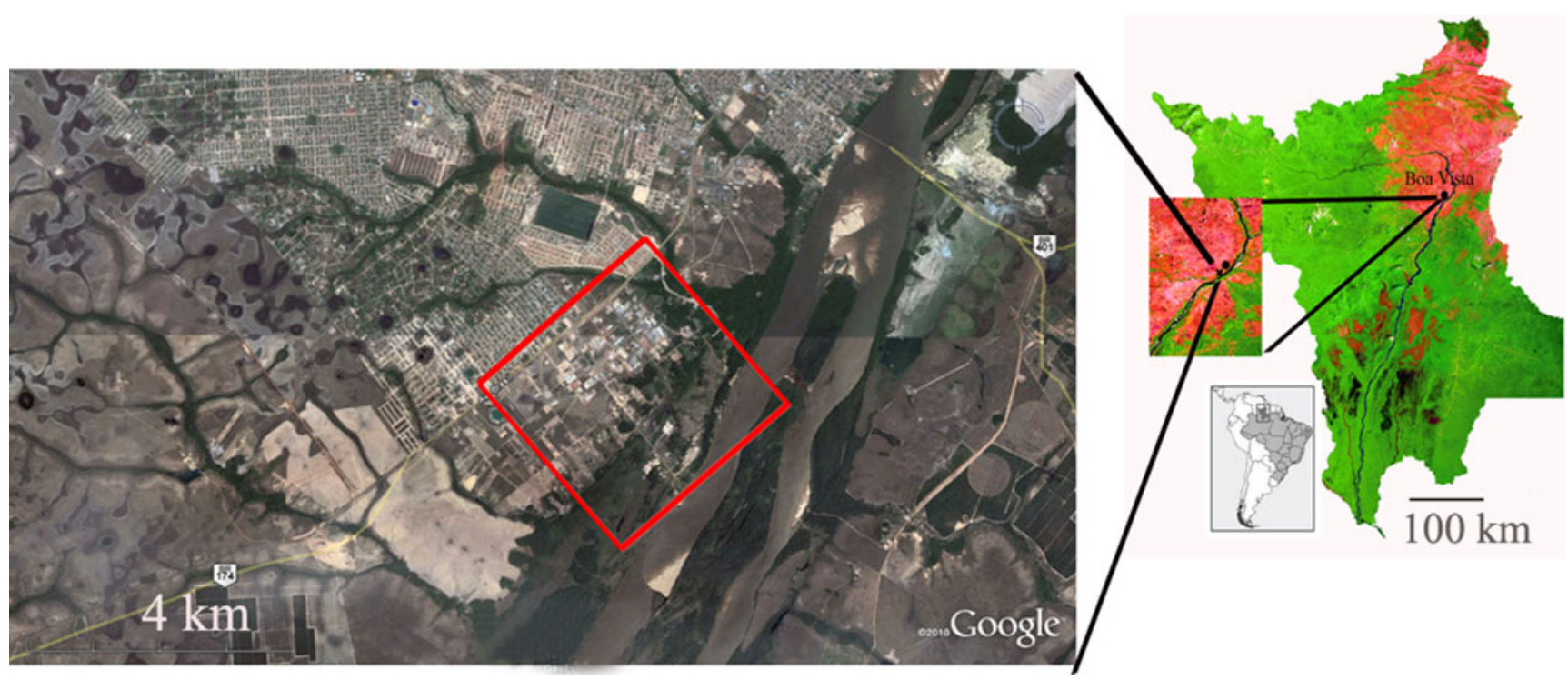

Fig 1 The study site, near Boa Vista, state of Roraima, in the northern Brazilian Amazon. Jardim das Copaíbas is located at the margins of the Branco River. 
Table 1 Total monthly rainfall $\left(\mathrm{mm} / \mathrm{m}^{2}\right)$, mean daily temperature and mean night humidity from August 2003-July 2004.

\begin{tabular}{lccc}
\hline Month & $\begin{array}{l}\text { Mean daily } \\
\text { temperature }\left({ }^{\circ} \mathrm{C}\right)\end{array}$ & $\begin{array}{l}\text { Mean night } \\
\text { humidity }(\%)\end{array}$ & $\begin{array}{l}\text { Monthly rainfall } \\
\left(\mathrm{mm} / \mathrm{m}^{2}\right)\end{array}$ \\
\hline Aug & 27.0 & 57.6 & 55.1 \\
Nov & 26.1 & 61.1 & 33.3 \\
Jan & 26.6 & 55.3 & 4.8 \\
Mar & 27.1 & 53.6 & 13.3 \\
May & 25.9 & 58.4 & 280.5 \\
Jul & 25.7 & 61.6 & 300.1 \\
\hline
\end{tabular}

\section{Entomological survey}

Adult collections were conducted during six bimestrial field collections from August 2003 to July 2004, including November 2003, January 2004, March 2004 and May 2004. Mosquitoes were captured on the act of landing in 10 mosquito collection stations distributed within the village. Mosquitoes from all collection stations and from all sampling times were dissected. Collectors were placed inside houses, and at 30 and $>50 \mathrm{~m}$ away from the nearest house. Collectors exposed their arms and legs and mouthaspirated landing mosquitoes, under a protocol approved by the Ethics Committee of the "Fundação Oswaldo Cruz". Twelve-hour collections were performed in the peridomicile for two nights. For the $12 \mathrm{~h}$ collections, a team of three collectors captured mosquitoes for six continuous hours. These collectors were substituted by another team of three collectors that carried out sampling for the remaining $6 \mathrm{~h}$. On another two nights, mosquitoes were collected indoors and in the peridomicile from 18:00 to 22:00 h. The number of collectors per night varied from six to 10. A minimum of 120 man-hour of collections were performed on each collection period. Adult mosquitoes were identified using taxonomic keys (Consoli \& Lourenço-de-Oliveira 1994). Further methodological details regarding mosquito collections have been described elsewhere (Barros \& Honório 2007).

\section{Epidemiological models: sporozoite rates and entomological inoculation rates}

The mathematical models were based on Macdonald (1957) to facilitate their use by non-statisticians. Although more complex equations have been proposed (Molineaux et al 1988), the results provided are basically the same. The likelihood of a mosquito being infectious ( $S=$ sporozoite rate) can be derived by the equation: $S=\frac{P^{n} a x}{a x-\log _{e} P}$, where $P=$ the probability of survival during 1 day; $n=$ the duration in days of the extrinsic cycle of the parasite in the mosquito (e.g. usually nine or 10 for Plasmodium vivax); $a$ is the average number of bites per day of a single vector (e.g. 0.5 , if it feeds every 2 days); $x=$ the proportion of bites on infective persons which result in infection of the vector. The expected EIR was calculated by multiplying the human biting rate by the sporozoite rate.

\section{Critical mosquito biting rates and vectorial capacities}

To better understand the relation of the sporozoite infection rates and malaria transmission, we studied the critical vector biting rates, obtained from the malaria reproduction indices ( $z$; Macdonald 1957). The malaria reproduction index reflects the number of secondary cases of malaria that result from a primary case, i.e. the number of humans that will be infected from a single case. In low-transmission areas (hypoendemic malaria), the index can be calculated as follows: $z=\frac{m^{2} b P^{n}}{-r \log _{e} P}$, where $m a$ is the vector density relative to humans (i.e. the man biting rate), estimated through the human biting rate, $b=$ proportion of bites that are infectious to humans, $r=$ the human recovery rate (the reciprocal of the number of days for recovery of an infected individual). Malaria reproduction rates $>1.0$ would enable the expansion of infections in a population, while those $<1.0$ indicate a decline in infections. Critical biting rates would be those which would result in a malaria reproduction rate of 1.0 . Critical biting rates ( $\mathrm{ma}^{\text {crit }}$ ) can be determined by a rearrangement of the malaria reproduction rate equation: $\mathrm{ma}^{\mathrm{crit}}=\frac{-r \log _{e} P}{\mathrm{abx}^{n}}$.

The vectorial capacities (VC), which describes the potential for transmitting malaria, were determined for each vector on every occasion by: $\mathrm{VC}=\frac{\mathrm{ma}^{2} P^{n}}{-\log _{e} P} \quad$ (WHO 2002). The VC is the same as the malaria reproduction rate considered on a daily basis. When two or more vectors are transmitting the same disease, the daily reproduction rate is equal to the sum of their individual VCs (WHO Expert Committee on Malaria 1966).

\section{Parameter estimates: mosquito dissections for survival rates and gonotrophic cycle duration}

Dissections were performed by the same trained entomologist during the collection period (FSM Barros). Parity was determined by verifying the state of the terminal tracheoles of the ovaries of adult mosquitoes and by determining the presence of follicular stalk dilatations through the Polovodova's technique (Detinova 1962). During the first oogenesis cycle of a mosquito, the terminal tracheole branches move further apart, as the ovary grows. This stretching is irreversible and allows for the identification of parous females by microscopic examination. Daily survival rates $(P)$ were calculated by Davidson's method as follows: $P-\sqrt[g]{\text { parity }}$, 
where parity represents the ratio between the number of parous mosquitoes and the total number of females collected, and $g$ =the duration of the gonotrophic cycle in days (Davidson \& Draper 1953). Daily survival rates correspond to the proportion of mosquitoes surviving 1 day. The duration of the gonotrophic cycle $(g)$, i.e. the time elapsed from one blood feeding to the next, can be calculated by adding the time elapsed from oviposition to blood feeding (estimated by examining the state of contraction of the terminal sections of the ovarioles after passage of mature eggs) and the time for egg development as indicated in Charlwood and Alecrim (1989) \& Charlwood et al (1997). Mosquitoes sacrificed more than $6 \mathrm{~h}$ after their capture were not considered because this could invalidate accurate estimates of the gonotrophic cycle duration (Barros et al 2007b). The time for egg development was taken from the literature (Charlwood 1980). Further methods for age-grading mosquitoes and more methodological details have been previously described (Barros et al 2007b).

\section{Other parameter estimates}

The average daily number of bites on men of a single vector $(a)$ was determined by the percentage of mosquitoes biting men, instead of other animals, divided by the duration of the gonotrophic cycle (Molineaux et al 1988). The percentage of mosquitoes biting men instead of other animals (a) was assumed to be $35 \%$ for both species, derived from the literature (Rachou 1958).

The susceptibility of mosquitoes to gametocyte infection and development of sporozoites in their salivary glands $(x)$ was calculated from laboratory dissection studies in the published literature (Klein et al 1991). For determining the proportion of bites that are infectious to humans $(b)$, all infected mosquitoes were assumed to transmit malaria effectively, i.e. only the value of $x$ was used in the formula. The duration of the sporogonic cycle $(n)$ was estimated by the Moshkovsky method (WHO 1975). First, the mean daily temperatures during the period of study are determined. The duration of the sporogonic cycle for $P$. vivax corresponds to the amount of days required accumulate $105^{\circ}$ per day. The value of the human recovery rate $(z)$ was taken from the literature and assumed to be the same for both species. Since it takes an average of 3-7 days to recover from malaria, the duration of sickness/illness can be calculated as $r=1 / 7=0.143$ (Kamugisha 1992).

\section{Results and Discussion}

A total of $180 \mathrm{~A}$. darlingi and $726 \mathrm{~A}$. albitarsis E were captured and dissected during six collecting periods and their biting rates and remaining parameters proposed for this work were calculated (Table 2).

\section{Sporozoite rates and critical vector biting rates}

Malaria control strategies require data to estimate relative reductions in mosquito mortality, emergence or human biting rates. Field data measuring EIR of Amazonian vector species have sometimes determined values that are so low that these parameters would not be practical indicators of the efficacy of control campaigns (Girod et al 2008, Moreno et al 2009). Therefore, it may be more advantageous to have consistent estimates of epidemiological parameters, such as survival rates, that permit estimating sporozoite rates, even if the "gold standard" of determining EIR from human landing catches provides a more accurate estimate (Smith \& McKenzie 2004). We have previously demonstrated that parity rates can vary in different seasons (Barros et al 2007b). We also reported that malaria incidence may be better correlated with survival rates than adult mosquito density (Barros et al 2011c). It has been suggested that heavy rainfall has an effect on adult mortality (Bruyning 1952) and Barros et al (2011c) found a significant association between the number of wet days per month and mosquito parity.

In the present study, we determined that $A$. darlingi and $A$. albitarsis $\mathrm{E}$ had relatively similar survival rates $(P)$ (Table 2). Anopheles darlingi had higher sporozoite rates and lower critical vector biting rates, indicating that lower numbers of mosquitoes of this species would be necessary for initiating epidemic malaria transmission. However, the VC of $A$. albitarsis $\mathrm{E}$ was higher than that of $A$. darlingi on every collection (Table 2). The higher estimated sporozoite rates for $A$. darlingi were primarily due to the differences in susceptibility to sporozoite infection $(x)$. Because of its efficiency in transmitting both $P$. vivax and $P$. falciparum, very low biting rates of $A$. darlingi have been found to be enough for maintaining malaria transmission (Rubio-Palis \& Zimmerman 1997, Lounibos \& Conn 2000). In this study, A. darlingi also had a lower critical vector biting rate, indicating that lower numbers of this mosquito would be needed for initiating epidemic malaria transmission (Table 2). The results suggest that the initial autochthonous cases in our study area, at the time of sampling, would most likely be transmitted by $A$. darlingi. Similar results have been suggested by Tadei \& Thatcher (2000). A systematically higher vectorial capacity at the study site means that $A$. albitarsis $\mathrm{E}$ contributes more to malaria reproduction rate than $A$. darlingi. Although $A$. darlingi has higher sporozoite rates, the higher densities of $A$. albitarsis $\mathrm{E}$ at the study area account for the higher EIR's of this species (Table 2). 
Table 2 Parameter estimates and values of critical biting rates and sporozoite rates of Anopheles darlingi and Anopheles albitarsis $\mathrm{E}$ per collection period.

\begin{tabular}{|c|c|c|c|c|c|c|c|c|c|c|c|c|}
\hline \multirow{2}{*}{$\begin{array}{l}\text { Month } \\
\text { Anopheline species }\end{array}$} & \multicolumn{2}{|l|}{ Aug } & \multicolumn{2}{|l|}{ Nov } & \multicolumn{2}{|l|}{ Jan } & \multicolumn{2}{|l|}{ Mar } & \multicolumn{2}{|l|}{ May } & \multicolumn{2}{|l|}{ Jul } \\
\hline & dar & $a l b$ & dar & $a l b$ & dar & $a l b$ & dar & $a l b$ & dar & $a l b$ & dar & $a l b$ \\
\hline Man biting rates $(m a)$ in bites/man/hour & 2.06 & 20.92 & 0.28 & 22.89 & 1.88 & 9.85 & 0.47 & 1.41 & 3.85 & 5.63 & 8.35 & 7.41 \\
\hline Probabilities of surviving one day $(P)$ & 0.81 & 0.80 & 0.83 & 0.80 & 0.81 & 0.78 & 0.91 & 0.86 & 0.88 & 0.87 & 0.80 & 0.83 \\
\hline Extrinsic cycle durations in days $(n)$ & 8.14 & 8.14 & 7.34 & 7.34 & 7.29 & 7.29 & 7.24 & 7.24 & 8.68 & 8.68 & 9.13 & 9.13 \\
\hline Gonotrophic cycle durations $(g)$ & 2.30 & 2.63 & 2.30 & 2.63 & 2.30 & 2.63 & 2.30 & 2.63 & 2.30 & 2.63 & 2.30 & 2.63 \\
\hline Proportion of bites on man infectious to mosquitoes $(x)$ & 0.82 & 0.58 & 0.82 & 0.58 & 0.82 & 0.58 & 0.82 & 0.58 & 0.82 & 0.58 & 0.82 & 0.58 \\
\hline Number of blood meals per vector per day $(a)$ & 0.15 & 0.13 & 0.15 & 0.13 & 0.15 & 0.13 & 0.15 & 0.13 & 0.15 & 0.13 & 0.15 & 0.13 \\
\hline Critical biting rates (mosquitoes/man/night) (ma ${ }^{\text {crit }}$ ) & 1.36 & 4.52 & 0.90 & 3.40 & 1.57 & 5.94 & 0.27 & 1.51 & 0.62 & 1.41 & 1.98 & 3.44 \\
\hline Sporozoite rate $(S)$ & 0.08 & 0.04 & 0.11 & 0.05 & 0.07 & 0.03 & 0.28 & 0.11 & 0.15 & 0.11 & 0.05 & 0.05 \\
\hline Vectorial capacity (VC) & 0.32 & 0.29 & 0.07 & 0.06 & 0.25 & 0.28 & 0.36 & 0.38 & 1.33 & 1.41 & 0.90 & 0.82 \\
\hline EIR & 0.16 & 0.85 & 0.03 & 1.22 & 0.13 & 0.33 & 0.13 & 0.15 & 0.57 & 0.63 & 0.46 & 0.38 \\
\hline
\end{tabular}

dar=Anopheles darlingi, alb=Anopheles albitarsis $\mathrm{E}$.

\section{Method limitations: parameter estimates}

Our study has a number of methodological limitations. Parameter estimates obtained in the study were designed only for comparative analysis between vector species and cannot be considered absolute values for comparison with other samples. The lack of experimental data available on some parameters meant that they had to be estimated from the literature.

One important parameter to be considered for critical density calculations is the proportion of mosquito bites that are infectious to humans $(b)$. In the present study, it was assumed that all bites from sporozoite-positive mosquitoes were infectious to humans, effectively transmitting malaria. However, it has been suggested that transmission efficiency is much lower and that there is variation among Plasmodium species. In the Garki Project in West Africa, this parameter was estimated to be $0.097 \pm 0.017$ (Molineaux \& Gramiccia 1980). To our knowledge, the only available estimate of $b$ with South American vectors was determined by Rubio-Palis et al (1992). Only 0.0032 of $P$. vivax CS protein-positive mosquitoes would result in clinically evident malaria, while 0.202 of bites from Plasmodium falciparum CS proteinpositive mosquitoes would result in infection. No variation has yet been reported among mosquito species. If the critical vector densities are corrected with these values $(b=0.0032$. $x)$, much higher critical biting rates would be obtained for both $A$. darlingi and $A$. albitarsis $E$. Another parameter, the human biting rate $(a)$, was not controlled for and was assumed to be the same for both species. A percentage of only $35 \%$ of mosquitoes were assumed to be biting man instead of other animals. Since the area is rather densely inhabited and most of the forest has been destroyed, this represents a low value and possibly higher values would be more likely. Bustamante et al (1951) \& Oliveira-Ferreira et al (1992) reported that around $65-70 \%$ of $A$. darlingi were found biting man. We are unaware of human biting rate determinations for $A$. albitarsis $E$. For that reason, we decided to use the same biting rate for both species. However, we have verified that, although both species are anthropophilic, $A$. darlingi is more anthropophilic than $A$. albitarsis $\mathrm{E}$ in this area (Barros et al 2010). If $A$. darlingi is indeed associated with higher values of $a$, as compared to $A$. albitarsis $\mathrm{E}$, an even greater discrepancy in the sporozoite rates and critical biting rates of each species can be expected (Table 2 ).

The susceptibility of a mosquito species to sporozoite infections may be the most important factor determining its epidemiological importance. The susceptibility of mosquitoes to sporozoite infections $(x)$ was obtained from the literature, where they were estimated under laboratory studies. To our knowledge, there are no studies that have corroborated these values in the field. Also, the study by Klein et al (1991) was performed on A. albitarsis latu sensu (I.s.) from Rondonia, Brazil, while we sampled $A$. albitarsis E. Another point to consider is the method for determining species-specific mosquito infection rates. We chose to use salivary gland dissection for determining sporozoite infection rates. It may be argued that ELISA or Vectest ${ }^{\circledR}$ are more sensitive than salivary gland dissections for the determination of sporozoite infection rates, but the latter may be more specific (Beier et al 1990). It is possible that some mosquitoes tested positive by ELISA may not be truly infectious, especially when processing both the head and thorax of the mosquito. This could be due to an insufficient number of infective sporozoite stages inside their salivary glands (Klein et al 1991, Vasconcelos et al 2002). Until a better understanding of the significance of the CS protein-positive mosquito pool is available, we believe the use of salivary gland 
dissection could be favored in areas with high sporozoite infection rates while CS protein tests would still be more practical in areas with a low prevalence.

\section{Method limitations: classic model simplification only for low transmission}

The classic models provide a starting point for quantifying malaria transmission and for relating static and dynamic aspects of malaria infection in humans and mosquitoes, but the underlying epidemiology of malaria is more complicated. The Ross-Macdonald model was used in the present study due to its simplicity.

We believe that higher sporozoite rates or EIR found with a potential vector species during high transmission periods may not necessarily mean that the potential vector species is the more important vector in the studied region. The potential vector with higher EIR may be performing as a more efficient vector at that specific moment, but the same may not be true if there were changes in the biting rates or the prevalence of malaria in the human population. We caution against the use of the term "primary vectors" for these potential species, especially in areas with $A$. darlingi, until their role in malaria transmission dynamics is better characterized, as proposed with $A$. marajoara in Serra do Navio (Póvoa et al 200ob) and A. albitarsis E in Roraima (Póvoa et al 2006).

\section{Longitudinal analysis of the study of Vasconcelos et al (2002)}

During a malaria epidemic in the same area as the present study, Vasconcelos et al (2002) observed higher EIR for $A$. albitarsis $\mathrm{E}$, with 6.9 infective bites/ person/year as compared to 1.65 positive bites/person/ year for $A$. darlingi. These rates were determined when malaria prevalence was high in the population. The higher sporozoite rates of $A$. albitarsis $\mathrm{E}$ may reflect the unusually high biting rates encountered at that time, representing approximately $67 \%$ of the total number of captured mosquitoes, while $A$. darlingi represented only $5.3 \%$.

Analyzing the longitudinal determination of EIR reported by Vasconcelos et al (2002) in Boa Vista (Fig 2), it can be verified that, although $A$. albitarsis $E$ reached higher infection rates after the epidemic peaks had started, $A$. darlingi infection preceded that of the former species on every occasion. Three malaria transmission peaks occurred during the 2-year observation period (unpublished data). If consideration is given solely to the EIR data, one could conclude that $A$. albitarsis $\mathrm{E}$ was the most important vector in the area.
However, we suggest that $A$. darlingi may be important for initiating epidemic malaria transmission. When malaria becomes more prevalent in the human population, A. albitarsis $\mathrm{E}$ would assume a more important role, as a function of its higher biting rates.

Anopheline distribution in roraima and malaria prevalence, ELISA-positive species and $A$. darlingi

We have reported anopheline distributions in Roraima (Barros et al 2007b). This state differs from other regions in the Amazon because of dry-land colonization projects predominate instead of riverine settlements on the banks of large rivers. Frontier zone malaria appears to differ epidemiologically from alluvial or riverine malaria (Barros et al 2011a) and malaria transmission in the savanna may have its particularities. Despite the wide distribution of $A$. albitarsis I.s. over the entire savanna area, which covers most of the northeast corner of the state, the most densely populated area, malaria is almost completely absent in this ecosystem. Other species, such as Anopheles triannulatus I.s. (Neiva \& Pinto) and Anopheles nuneztovari (Gabaldon) also breed abundantly in the savanna, while $A$. darlingi is completely absent in this ecosystem (Nagm et al 2007). Anopheles darlingi is restricted to areas with rivers and riparian vegetation (Rubio-Palis \& Zimmerman 1997). All recorded important malaria foci in Roraima have occurred in these areas (Barros et al 2007b, Nagm et al 2007). Barros et al (2011b) have proposed that the species prefers shaded areas, proximity to human dwellings and microdams, and that the ideal conditions can be found at forested-deforested transitions. We believe that the same ideal breeding conditions may be present in savannaforest interfaces. The preference for shade may be particularly important for explaining the absence of $A$. darlingi in the savanna.

The observed epidemiological picture of malaria in state of Roraima suggests that the density of $A$. albitarsis $\mathrm{E}$ necessary to initiate and maintain malaria transmission, independent of the presence of $A$. darlingi, may not occur in this region, although the latter is theoretically possible. Similarly, the potential vectors $A$. nuneztovari and $A$. triannulatus I.s., although giving positive results with the ELISA tests, may be incapable of causing outbreaks of malaria in the state of Amazonas in the absence of $A$. darling (Tadei \& Thatcher 2000). Both Anopheles oswaldoi (Peryassu) and Anopheles mediopunctatus (Theobald) have also been reported to develop infective sporozoites in the laboratory (Marelli et al 1999, Klein et al 1991). However, A. oswaldoi develops infective sporozoites at very low rates $(<7 \%)$. Although a high percentage of $A$. oswaldoi has been found naturally infected in the state of Acre in the Brazilian amazon basin, this was reported in the presence of very high biting rates, over 70 times that of A. darlingi in the same area (Branquinho et al 1996). 


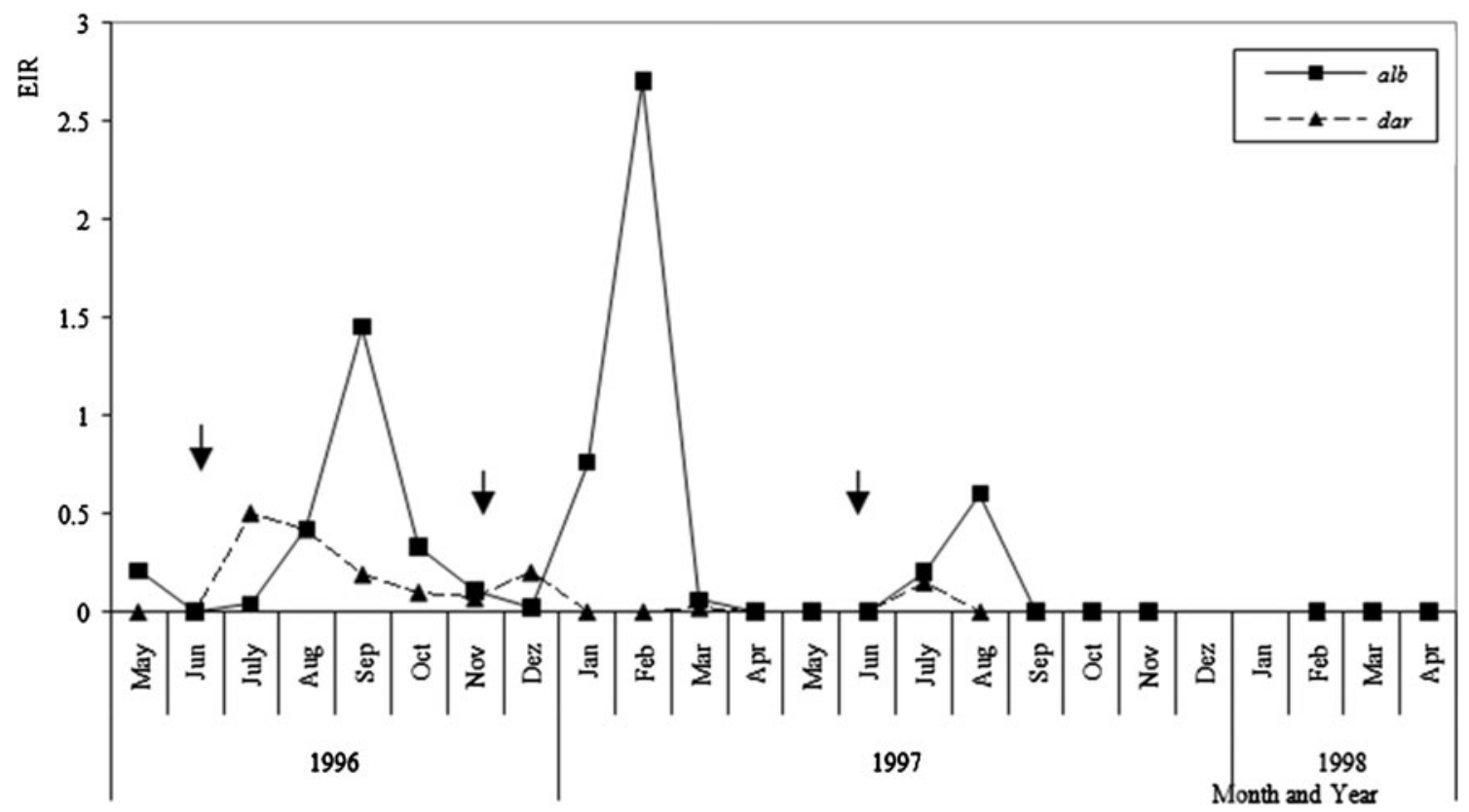

Fig 2 Entomological inoculation rates of Anopheles darlingi (triangles) and Anopheles albitarsis E (squares) in Boa Vista, Roraima, Brazil (modified from Vasconcelos et al 2002). Anopheles darlingi infection precedes A. albitarsis E infection at the three malaria transmission peaks (arrows).

\section{Suggestions for future EIR studies}

We suggest that researchers studying EIR's of potential vectors should correlate their results with ovarian dissection studies to determine the percentage of parous females and survival rates. This simple procedure would enable an estimation of critical man-biting rates of the vector species needed for initiating malaria transmission (Smith \& McKenzie 2004). Studies that report EIR's should also describe the prevalence of human malaria at the time of sampling and vectors found positive in high malaria prevalence settings must be differentiated from the ones found in low prevalence situations.

\section{Critical vector densities for control strategies}

The knowledge of critical vector densities may have important implication for malaria control. We suggest that, through studies determining species-specific parameter estimates, the adult female biting rates at which each mosquito species becomes epidemiologically important can be determined and used to quantify the role of each species in a transmission area. These procedures could enable a better understanding of malaria transmission in endemic and epidemic situations.

Critical vector biting rates would not be static figures, but a species-specific function of mosquito survival, gonotrophic cycle duration and the presence of alternative sources of blood in the area. Control efforts could consist of increased surveillance of human malaria cases in areas where the biting rate of vector species are above their critical densities. Alternatively, the efficiency of control strategies, such as insecticide spraying or treating breeding sites of target species, can be monitored by using density and survival data to verify if mosquito biting rates have been decreased below their critical density levels. Even preventive measures become feasible.

The current data available suggests that the status of an anopheline species as a malaria vector in nature may be a function of the epidemiological setting. The terms "primary" and "secondary" or "potential" vectors in current use in the literature are relatively imprecise and have been used to indicate that some species have higher EIR than others. Our data, as well as that of other authors (Tadei \& Thatcher 2000), suggest that $A$. darlingi may have an important role in "initiating" epidemic malaria transmission due to its ability in transmitting malaria at lower mosquito densities, when disease prevalence is low in the population. Other species, the "secondary" or "potential" vectors, could be able to maintain transmission levels when higher mosquito biting rates and/or disease prevalence become available.

The methods presented here may help to shed light in the importance of different anopheline species in malaria transmission in the Amazon. To our knowledge, this is the first proposition of the use of mathematical formulae to quantify the role of Neotropical secondary vectors in malaria transmission. We believe that more studies are necessary to verify these results. 
Acknowledgments The authors would like to thank José Francisco Luitgards Moura, for the kind welcoming to his laboratory and to Ulisses Confalonieri for the constant support during field work. This work is dedicated to the mosquito entomology personnel in Roraima, especially Ducineia B. de Aguiar, Luiz Oswaldo, Pedro R. da Silva, Janylene S. Gomes, Valdenor Macedo, Gerson Francisco, Davi R. Galvão and Muniz, for their fine work in collecting accurate field data and their groundbreaking insights. Thanks also to the Inter-American Institute for Global Change Research (IAI; grant CRN 048) for funding this research.

\section{References}

Arruda ME, Carvalho MB, Nussenzweig RS, Maracic M, Ferreira W, Cochrane AH (1986) Potential vectors of malaria and their different susceptibility to Plasmodium falciparum and Plasmodium vivax in northern Brazil identified by immunoassay. AmJTrop Med Hyg $35: 873-881$

Barbosa RI, Ferreira EJG, Castellón EG (1997) Homem, Ambiente e Ecologia no Estado de Roraima. INPA, Manaus, p 613

Barros FSM, Honório NA (2007) Man biting rate seasonal variation of malaria vectors in Roraima, Brazil. Mem Inst Oswaldo Cruz 102:299-302

Barros FSM, Aguiar DB, Rosa-Freitas MG, Luitgards-Moura JF, Gurgel HC, Honório NA, Arruda ME, Tsouris P, Vasconcelos SD (2007a) Distribution summaries of malaria vectors in the Northern Brazilian Amazon. J Vector Ecol 32:161-167

Barros FSM, Arruda ME, Vasconcelos SD, Luitgards-Moura JF, Confalonieri $U$, Rosa-Freitas Tsouris $P$, Lima-Camara $T$, Honório NA (2007b) Parity and age composition for Anopheles darlingi Root (Diptera: Culicidae) and Anopheles albitarsis Lynch-Arribálzaga (Diptera: Culicidae) of the northern Amazon Basin, Brazil. J Vector Ecol 32:1-15

Barros FSM, Arruda ME, Honório NA (2010) Mosquito anthropophily: implications on malaria transmission in the Northern Brazilian Amazon. Neotrop Entomol 39:1039-1043

Barros FSM, Honório NA, Arruda ME (2011a) Temporal and spatial distribution of malaria within an agricultural settlement of the Brazilian Amazon. J Vector Ecol 36(1):159-169

Barros FSM, Arruda ME, Gurgel HC, Honório NA (2011b) Spatial clustering and longitudinal variation of Anopheles darlingi (Diptera: Culicidae) larvae in a river of the Amazon: the importance of the forest fringe and of obstructions to flow in frontier malaria. Bull Entomol Res 101(6):643-658

Barros FSM, Arruda ME, Gurgel HC, Honório NA (2011C) Survivorship of Anopheles darlingi (Diptera: Culicidae) in relation with malaria incidence in the Brazilian Amazon. Plos One 6(8):e22388.

Beier JC, Perkins PV, Koros JK, Onyango FK, Gargan TP, Wirtz RA, Koech DK, Roberts CR (1990) Malaria sporozoite detection by dissection and ELISA to assess infectivity of afrotropical Anopheles (Diptera: Culicidae). J Med Entomol 27:377-382

Branquinho MS, Araujo MS, Natal D, Marrelli MT, Rocha RM, Taveira FA, Kloetzel JK (1996) Anopheles oswaldoi a potential malaria vector in Acre, Brazil. Trans R Soc Trop Med Hyg 90:233

Bruyning CFA (1952) Some observations on the distribution of $A n$. darlingi Root in the savanna region of Suriname. Doc Med Geogr Trop 4:171-174

Burkot TR, Graves PM (1995) The value of vector-based estimates of malaria transmission. Ann Trop Med Parasitol 89:125-134

Bustamante FM, Pinto O, Geledes XSH, Freitas JR (1951) Sobre a captura do Anopheles darlingi e do Anopheles albitarsus nas paredes externas de casas detetizadas em Engenheiro Dolabela, Minas Gerais. Rev Bras Malar 3:122-129
Charlwood JD (1980) Observations on the binomics of Anopheles darlingi Root (Diptera: Culicidae) from Brazil. Bull Entomol Res 70:685-692

Charlwood JD, Alecrim WA (1989) Capture-recapture studies with the South American malaria vector Anopheles darlingi, Root. Ann Trop Med Parasitol 83:569-576

Charlwood JD, Smith T, Billingsley PF, Takken W, Lyimo EOK, Meuwissen JHET (1997) Survival and infection probabilities of anthropophagic anophelines from an area of high prevalence of Plasmodium falciparum in humans. Bull Entomol Res $87: 455-453$

Consoli RAGB, Lourenço-de-Oliveira R (1994) Principais mosquitos de importância sanitária no Brasil. Fiocruz, Rio de Janeiro, p 224

Davidson G, Draper C (1953) Field studies of some of the basic factors concerned in the transmission of malaria. Trans Royal Soc Trop Med Hyg 47:522-535

Detinova TS (1962) Age-grouping methods in Diptera of medical importance. Monographic series no. 47. World Health Organization, Geneva, p 215

Flores-Mendoza C, Fernández R, Escobedo-Vargas KS, Vela-Pérez $Q$, Schoeler GB (2004) Natural Plasmodium infections in Anopheles darlingi and Anopheles benarrochi (Diptera: Culicidae) from eastern Peru. J Med Entomol 41:489-494

Galardo AKR, Arruda M, Couto AARD, Wirtz R, Lounibos LP, Zimmerman RH (2007) Malaria vector incrimination in three rural riverine villages in the Brazilian Amazon. AmJTrop Med Hyg 76:461-469

Gil LHS, Tada MS, Katsuragawa TH, Ribolla PEM, Pereira-Da-Silva LH (2007) Urban and suburban malaria in Rondônia (Brazilian Western Amazon) II. Perennial transmissions with high anopheline densities are associated with human environmental changes. Mem Inst Oswaldo Cruz 102:271-276

Girod R, Gaborit P, Carinci R, Issaly J, Fouque F (2008) Anopheles darlingi bionomics and transmission of Plasmodium falciparum, Plasmodium vivax and Plasmodium malariae in Amerindian villages of the Upper Maroni Amazonian Forest, French Guiana. Mem Inst Oswaldo Cruz 103:702-710

Kamugisha J (1992) Report on the Malariometric Survey in Kabarole district. Epidemiology Unit Ministry of Health, Uganda, pp 1-36

Klein TA, Lima JBP, Tada MS, Miller R (1991) Comparative susceptibility of anopheline mosquitoes in Rondônia Brazil, to infection by Plasmodium vivax. AmJTrop Med Hyg 45:463-470

Lounibos LP, Conn JE (2000) Malaria vector heterogeneity in South America. Am Entomol 46:237-248

Macdonald G (1957) The epidemiology and control of malaria. Oxford University Press, London, p 201

Magris M, Rubio-Palis Y, Menares C, Villegas L (2007) Vector bionomics and malaria transmission in the Upper Orinoco River, Southern Venezuela. Mem Inst Oswaldo Cruz 102:303-311

Marelli MT, Honorio NA, Flores-Mendoza C, Lourenço-de-Oliveira R, Marinotti R, Kloetzel JK (1999) Comparative susceptibility of two members of Anopheles oswaldoi complex, Anopheles oswaldoi and Anopheles konderi, to infection by Plasmodium vivax. Trans $\mathrm{R}$ Soc Trop Med Hyg 93:381-384

Molineaux L, Gramiccia G (1980) The Garki Project: research on the epidemiology and control of malaria in the Sudan savanna of West Africa. World Health Organization, Geneva, p 311

Molineaux L, Muir DA, Spencer HC, Wernsdorfer WH (1988) The epidemiology of malaria and its measurement, p. 999-1088. In: Wernsdorfer WH, McGregor I (eds) Malaria: principles and practice of malariology. Churchill Livingstone, Edinburgh, Scotland, pp 9991090

Moreno JE, Rubio-Palis $Y$, Páez $E$, Pérez $E$, Sánchez $V$, Vaccari $E$ (2009) Malaria entomological inoculation rates in gold mining areas of Southern Venezuela. Mem Inst Oswaldo Cruz $104: 764-768$ 
Póvoa MM, Wirtz RA, Lacerda NRL, Miles MA, Warhurst D (2000a) Malaria vectors in the municipality of Serra do Navio, state of Amapá, Amazon region, Brazil. Mem Inst Oswaldo Cruz 93:179-184

Póvoa MM, Souza RTL, Lacerda NRL, Santa Rosa E, Galiza D, Souza JR, Wirtz RA, Schlichting CD, Conn JE (2006) The importance of Anopheles albitarsis $\mathrm{E}$ and Anopheles darlingi in human malaria transmission in Boa Vista, state of Roraima. Brazil Mem Inst Oswaldo Cruz 101:163-168

Nagm L, Luitgards-Moura JF, Neucamp CS, Barros FSM, Honório NA, Tsouris P, Rosa-Freitas MG (2007) Anopheline breeding sites around Boa Vista, Roraima, 2004-2005, an apraisal. Rev Inst Med Trop São Paulo 49:309-316

Oliveira-Ferreira J, Lourenço-de-Oliveira R, Deane LM, Daniel-Ribeiro CT (1992) Feeding preference of Anopheles darlingi in malaria endemic areas of Rondônia State-northwestern Brazil. Mem Inst Oswaldo Cruz 87:601-602

Póvoa MM, Silva ANM, Santos CCB, Segura MNO, Machado RLD (200ob) Malaria transmission. Ciência e Cultura 52:208-212

Rachou RG (1958) Anofelinos do Brasil. Comportamento das espécies vetoras de malária. Rev Bras Malariol Doenças Trop 10:145-181

Rosa-Freitas MG, Tsouris $P$, Peterson AT, Honório NA, Barros FSM, Aguiar DB, Gurgel HC, Arruda ME, Vasconcelos SD, Luitgards-Moura JF (2007) An ecoregional classification for the State of Roraima,
Brazil. The importance of landscape in malaria biology. Mem Inst Oswaldo Cruz 102:349-356

Rubio-Palis Y, Zimmerman RH (1997) Ecoregional classification of malaria vectors in the neotropics. J Med Entomol 34: 499-510

Rubio-Palis Y, Wirtz RA, Curtis CF (1992) Malaria entomological rates in Western Venezuela. Acta Trop 52:167-174

Smith DL, McKenzie FE (2004) Statics and dynamics of malaria infection in Anopheles mosquitoes. Malar J 3:13-17

Tadei WP, Thatcher BD (2000) Malaria vectors in the Brazilian Amazon: Anopheles of the subgenus Nyssorhynchus. Rev Inst Med Trop São Paulo 42:87-94

Vasconcelos AS, Kato MYN, Mourão EN, Souza RTL, Lacerda RNL, Sibajev A, Tsouris P, Póvoa MM, Momen H, Rosa-Freitas MG (2002) Biting indices, host-seeking activity and natural infection rates of anopheline species in Boa Vista, Roraima, Brazil from 1996 to 1998. Mem Inst Oswaldo Cruz 97:151-161

WHO Expert Committee on Malaria (1966) World Health Organization Technical Report Series, 324. World Health Organization, Geneva, p 48 WHO (1975) Manual on practical entomology in malaria. Part II. World Health Organization, Geneva, p 191

WHO (2002) Malaria entomology and vector control. World Health Organization, Geneva, p 114 